\title{
Urinary ascites and anuria caused by bilateral fungal balls in a premature infant
}

\author{
J H Ku, M E Kim, Y S Jeon, N K Lee, Y H Park
}

Arch Dis Child Fetal Neonatal Ed 2004;89:F92-F94

A case is reported of anuria and urinary ascites secondary to bilateral ureteropelvic obstruction by fungal balls. Management consisted of bilateral nephrostomy drainage with local irrigation with amphotericin B, and systemic antifungal treatment without surgery. Aspiration by paracentesis was performed for the urinary ascites and continuous drainage through an $8 \mathrm{Fr}$ pig tail catheter for the urinoma. The literature on renal fungus balls in neonates and infants is reviewed.

$\mathrm{T}$ he most common urinary fungus is Candida, producing asymptomatic candiduria, cystitis, and, with renal involvement, systemic candidiasis, primary renal candidiasis, and bezoar formation. Most patients have underlying disease or risk factors that favour the occurrence of systemic candidiasis. Predisposing factors described in the literature are prematurity, use of broad spectrum antibiotics, and use of intravenous catheters. ${ }^{1}$ Renal fungal balls may be a cause of urinary tract obstruction and acute renal failure in these patients. Although several cases of anuria in premature neonates or infants secondary to bilateral ureteropelvic junction obstruction related to fungal balls have been reported, no cases of urinary ascites associated with fungal balls have been described. We report a unique case of anuria and urinary ascites in a premature infant secondary to bilateral ureteropelvic junction obstruction caused by fungal balls.

\section{CASE REPORT}

A 3 month old female infant presented with anuria for 23 hours and abdominal distension. The patient was born as the second twin at 30 weeks gestation and had been treated with broad spectrum antibiotics, parenteral nutrition, central vascular access, and mechanical ventilation for hyaline membrane disease in the neonatal intensive care unit for two months. One month after leaving intensive care, she was readmitted because of anuria and abdominal distension. Mild fever was observed, and laboratory data revealed a white blood cell count of $39.0 \times 10^{9}$ cells/l, haemoglobin concentration of $85 \mathrm{~g} / \mathrm{l}$, and creatinine concentration of $168.0 \mu \mathrm{mol} / \mathrm{l}$. Ultrasonography showed bilateral hydronephrosis with echogenic contents within the renal pelves, a large cystic mass in the left perinephric space, and ascites (fig lA). Antegrade pyelography showed both collecting systems to be dilated, with multiple filling defects and extravasations from the upper calyces of the left kidney (fig 1B). Computed tomography showed multiple, small, low density regions in both renal parenchymes, and high density material filled the dilated pelves. A urinoma in the left prerenal space and ascites in the pelvic cavity were also observed (fig 2). Percutaneous nephrostomy on both sides was performed immediately after antegrade pyelography, and urine specimens were sent for analysis and fungal culture. Urinalysis showed many yeast-like cells, and Candida albicans was cultured from the specimens. Systemic antifungal treatment with amphotericin B was started at a test dose of $0.1 \mathrm{mg} / \mathrm{kg}$. The dose was increased gradually in daily increments over a three day period until a full dose of $0.5 \mathrm{mg} / \mathrm{kg}$ was achieved. Both renal pelves were irrigated at a rate of $40 \mathrm{mg} / \mathrm{h}$ or $45 \mathrm{mg} / \mathrm{h}$ every five hours daily with amphotericin B solution $(50 \mathrm{mg} / \mathrm{l})$. Continuous irrigation with 1 litre of solution with a slow drip infusion was maintained in both renal pelves. Aspiration by paracentesis was also performed for the urinary ascites, and continuous drainage through an $8 \mathrm{Fr}$ pig tail catheter for the urinoma. After three weeks, the urinary tract obstructions were relieved, which was confirmed by ultrasonography and antegrade pyelography, and the percutaneous nephrostomy catheters were removed. Four weeks later, excretory urography showed good urinary drainage without filling defects within both renal pelves, and the $8 \mathrm{Fr}$ pig tail catheter was removed. Fungal cultures from the urine were negative, and the systemic antifungal treatment was stopped six weeks after it had been started. There were no serious side effects associated with the treatment. The baby was discharged and convalescence was uneventful at the six month follow up.

\section{DISCUSSION}

Systemic candidiasis after intensive care in premature newborns is a well recognised complication, and fungal obstruction of the upper urinary tract in infants is potentially fatal. However, the diagnosis of fungal obstruction in high risk neonates is difficult to make and is often delayed or missed as there are no specific clinical features. Young age, small size, the presence of candidaemia, and withholding antifungal treatment are poor prognostic factors of fungal obstructive uropathy in neonates and infants. ${ }^{2}$ Mortality in the cases reported to date has been lower after aggressive surgical and medical management. Because yeasts are not always identified in specimens obtained from patients, ultrasonography has been the most useful imaging modality in the early diagnosis of fungal balls.

For patients with renal fungus balls without complete obstruction, surgical intervention such as placement of a nephrostomy tube is rarely necessary. In non-obstructing bilateral fungal balls, treatment with a combination of liposomal amphotericin B and fluconazole may remove the balls and obviate the need for surgical intervention. ${ }^{4}$ Oral fluconazole may be a safe and effective alternative for the management of systemic candidiasis in neonates. ${ }^{5}$ Complications requiring surgery, such as urinary tract obstruction, are uncommon. However, if fungal balls are found to be causing pelvic obstruction, treatment by insertion of bilateral nephrostomy catheters, instillation of amphotericin B into the renal pelvis, and parenteral and/or oral administration of antifungal drugs should be started. ${ }^{6}$ No guidelines are yet available for the indication, the mode of treatment, and length of treatment in neonates and infants with obstructing fungal balls. Sometimes, surgical removal of bezoars may be necessary to eradicate the fungal infection,? but not all patients need such an intervention. ${ }^{8}$ 

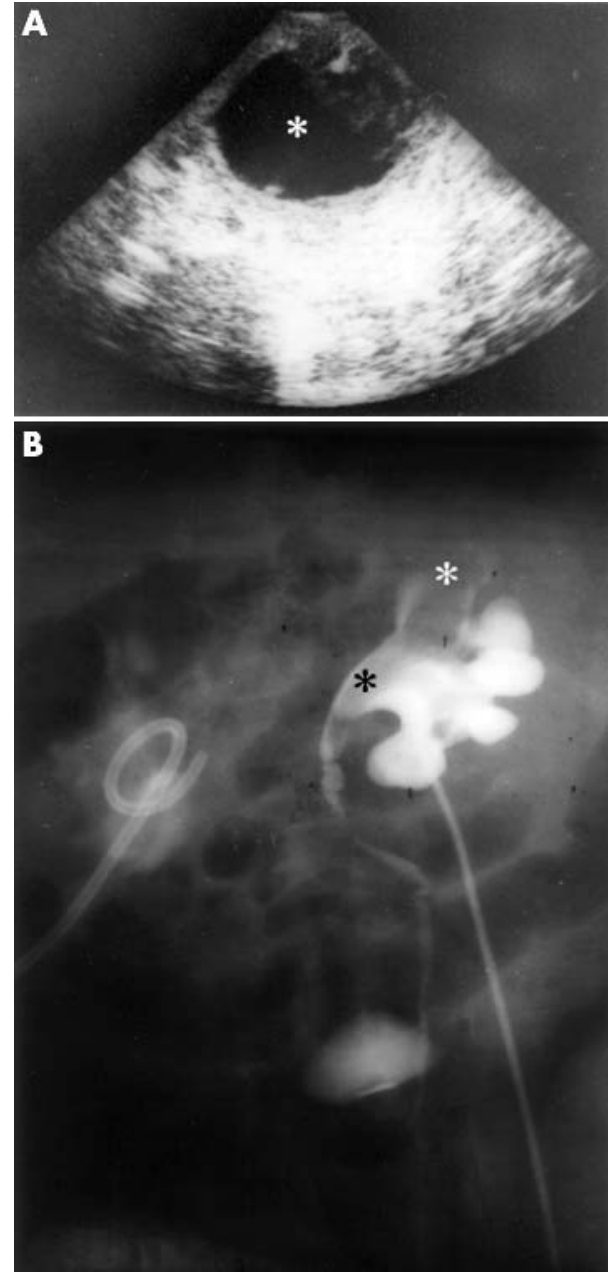

Figure 1 (A) Ultrasonograph showing a urinoma (asterisk) in the left prerenal space. (B) Left antegrade pyelography showing a dilated collecting system and multiple filling defects (black asterisk) in the renal pelvis, and extravasations (white asterisk) from the upper calyces.

Invasive fungal infections are a major cause of morbidity and mortality in premature newborns. Because it may not always be possible to remove risk factors, a high index of suspicion, prompt diagnosis, and early institution of antifungal treatment are recommended. Our patient was successfully treated with percutaneous nephrostomy and amphotericin B irrigation, coupled with systemic antifungal treatment without surgical removal. Urinary ascites were aspirated by paracentesis, and the urinoma was continuously drained through an 8 Fr pig tail catheter. Anuria resulting from fungal balls in the upper urinary system has rarely been

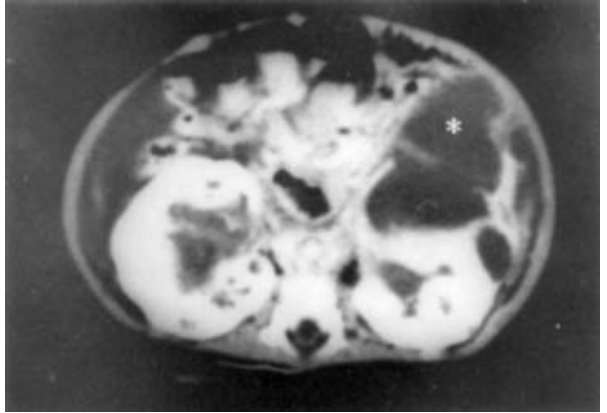

Figure 2 Computed tomography showing both multiple renal cysts in renal parenchymes and high density material filling dilated pelves. A urinoma measuring $3 \times 4 \mathrm{~cm}$ can be observed in the left prerenal space (asterisk).

reported. This is a very unusual case of anuria and urinary ascites in a premature infant caused by fungal balls.

\section{Authors' affiliations}

J H Ku, Department of Urology, Military Manpower Administration, Seoul, Korea

M E Kim, Department of Urology, Soonchunhyang University School of Medicine, Pucheon, Korea

Y S Jeon, N K Lee, Department of Urology, Soonchunhyang University School of Medicine, Chonan, Korea

Y H Park, Department of Urology, Soonchunhyang University School of Medicine, Seoul, Korea

Correspondence to: Dr Ku, Department of Urology, Military Manpower Administration, Joong-Ang Shin-geom so, San 159-1 Shin-gil 7 dong, Youngdeungpo-Ku, Seoul 150-057, Korea; randyku@hanmail.net

Accepted 5 February 2003

\section{REFERENCES}

1 Argyle C, Schumann GB, Genack L, et al. Identification of fungal casts in a patient with renal candidiasis. Hum Pathol 1984;15:480-1.

2 al-Rasheed SA. The management of fungal obstructive uropathy in neonates and infants. Ann Trop Paediatr 1994;14:169-75.

3 Bartone FF, Hurwitz RS, Rojas EL, et al. The role of percutaneous nephrostomy in the management of obstructing candidiasis of the urinary tract in infants. $J$ Urol 1988;140:338-41.

4 Stocker M, Caduff JH, Spalinger J, et al. Successful treatment of bilateral renal fungal balls with liposomal amphotericin B and fluconazole in an extremely low birth weight infant. Eur J Pediatr 2000;159:676-8.

5 Driessen M, Ellis JB, Muwazi F, et al. The treatment of systemic candidiasis in neonates with oral fluconazole. Ann Trop Paediatr 1997;17:263-71.

6 Pappu LD, Purohit DM, Bradford BF, et al. Primary renal candidiasis in two preterm neonates. Report of cases and review of literature on renal candidiasis in infancy. American Journal of Diseases in Children 1984;138:923-6.

7 Laufer J, Reichman B, Graif M, et al. Anuria in a premature infant due to ureteropelvic fungal bezoars. Eur J Pediatr 1986;145:125-7.

8 Hari P, Srivastava A, Gupta AK, et al. Neonatal renal failure due to obstructive candidal bezoars. Pediatr Nephrol 1997;1 1:497-8.

\section{PostScript}

\section{LETTERS}

\section{Cold comfort for babies}

CESDI Project 27/28 investigated the standards of care provided to infants who died after birth at 27-28 weeks gestation in England, Wales, and Northern Ireland during 1998-1999, comparing them with controls who survived. ${ }^{1}$ Temperature on admission to the neonatal unit was below the British Association of Perinatal Medicine/Royal College of Physicians (BAPM/RCP) standard of $36^{\circ} \mathrm{C}^{2}$ in $73 \%$ of babies who died and $59 \%$ of controls. The CESDI report confirms the findings of the EPICure study, ${ }^{3}$ which showed that low admission temperature was an independent risk factor for neonatal death after adjustment for other known risks. Alarmingly, the CESDI report concludes that, as most units were unable to achieve the standard, "the feasibility of achieving this standard must be questioned"! Vohra et $a l^{4}$ and Bjorklund and Hellstrom-Westas ${ }^{5}$ have shown that admission temperature is significantly increased if evaporative heat loss is prevented during resuscitation by occlusive wrapping after birth.

Since 2000, we have aimed to place all infants below 29 weeks gestation in polythene bags on the resuscitaire, before proceeding 
If you have a burning desire to respond to a paper published in the ADC or F\&N, why not make use of our "rapid response" option?

Log on to our website (www. archdischild. com), find the paper that interests you, click on "full text and send your response by email clicking on "submit a response".

Providing it isn't libellous or obscene, it will be posted within seven days. You can retrieve it by clicking on "read eletters" on our homepage.

The editors will decide, as before whether to also publish it in a future paper issue.

with their stabilisation. The policy was not followed universally at first, but since 2002 all babies below 29 weeks have been resuscitated in a plastic bag. The unit moved to a new hospital in March 2002, but there has been no change in delivery room temperature, or in the experience of medical and nursing staff attending resuscitation. Transport incubators were used in the old hospital to transfer the baby to the unit but this is now carried out on the resuscitaire.

The baby is slid into the bag up to the neck while still wet. The head is covered with a hat. No blankets are used, allowing radiant heat to warm the infant through the bag. Clinical inspection and auscultation can be performed through the bag, and, if vascular access is needed, a small hole can be cut in the bag. The infant is transported to the neonatal unit on the resuscitaire, eliminating the need for a transport incubator. Our resuscitaires have battery powered radiant heaters for the journey but these have not been important. The data shown here were gathered before the batteries were installed. Avoiding a move to a transport system has eliminated the associated risk of accidental extubation. On arrival in the unit, the baby is weighed and then placed in a warm humidified incubator before the bag is removed. Axillary temperature is then measured using an electronic thermometer.

Figure 1 shows the ranges of admission temperatures for inborn babies of 2328 weeks gestation, over the past eight years. Now that all babies are placed in a plastic bag, we have abolished hypothermia. The mean (SD) admission temperature is now $37.0(0.7)^{\circ} \mathrm{C}$. Some infants now have mildly raised temperature on admission. They are the subject of further study but in most there are markers suggesting maternal infection.

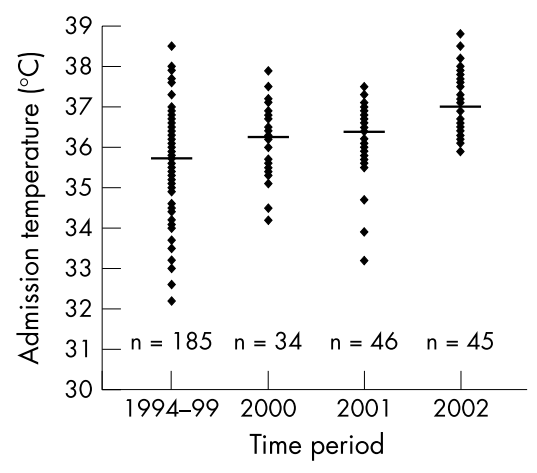

Figure 1 Ranges of admission temperatures for inborn babies of 23-28 weeks gestation.

Table 1 Neonatal blood values

\begin{tabular}{|c|c|c|c|}
\hline & $\begin{array}{l}\text { UA end diastolic flow } \\
\text { present (group 1; } \\
n=108 \text { ) }\end{array}$ & $\begin{array}{l}\text { UA end diastolic flow } \\
\text { absent (group 2; } \\
n=26 \text { ) }\end{array}$ & $\begin{array}{l}\text { UA end diastolic flow } \\
\text { reversed (group } 3 ; \\
n=45 \text { ) }\end{array}$ \\
\hline $\mathrm{WBC} / \mathrm{mm}^{3}(\times 1000)$ & $9.1(3.4)$ & 7. $3(2.6-54.2)$ & $7.8(2.3-44.6)$ \\
\hline Leucopenia & $6(5.6 \%)$ & $5(19.2 \%)$ & $5(11.1 \%)$ \\
\hline Leucocyłosis & $5(4.6 \%)$ & $4(15.4 \%)$ & $14(31.1 \%) \ddagger$ \\
\hline Haemoglobin (g/l) & $164(20)$ & $151(35) \dagger$ & $146(25) \dagger$ \\
\hline Packed cell volume (\%) & $52.1(6.5)$ & $48(11.5) \dagger$ & $46(8.7) \dagger$ \\
\hline Anaemia & $1(0.9 \%)$ & $2(7.7 \%)$ & $1(2.2 \%)$ \\
\hline Polycythaemia & $21(19.4 \%)$ & $4(15.4 \%)$ & $4(8.9 \%)$ \\
\hline Platelets $/ \mathrm{mm}^{3}(\times 1000)$ & $208.9(74.1)$ & $108(32-412)^{*}$ & $119(53.7)^{*}$ \\
\hline Thrombocytopenia & $4(3.7 \%)$ & $12(46.2 \%) \ddagger$ & $20(44.4 \%) \ddagger$ \\
\hline $\mathrm{NRBCs} / 100 \mathrm{WBCs}$ & $19(0-595)$ & $129(2-2890)^{*}$ & $247(12-1680)^{*}$, ,* \\
\hline $\begin{array}{l}\text { Raised NRBC count and } \\
\text { thrombocytopenia }\end{array}$ & $2(1.8 \%)$ & $11(42.3 \%) \ddagger$ & $20(44.4 \%) \neq \ddagger$ \\
\hline
\end{tabular}

Data are presented as mean (SD), median (range) or number (\%).

UA, Umbilical artery; WBC, white blood cell; NRBC, nucleated red blood cell. * $\mathrm{p}<0.05$ compared with group 1, ${ }^{* *} p<0.05$ compared with group 2 (all Mann-Whitney $U$ tests); $t p<0.05$ compared with group 1 (one tailed $t$ test); $\ddagger p<0.05$ compared with group 1 (Fisher's exact test).

Using this simple, inexpensive technique the BAPM/RCP standard is readily achieved, independent of the clinical state and size of the infant. All units should have a policy for auditing admission temperature and a strategy for eliminating hypothermia during resuscitation, as this may be just as important as other more complex and expensive interventions.

A J Lyon, B Stenson

Simpson Centre for Reproductive Health, Royal Infirmary of Edinburgh, Edinburgh, Scotland, UK; andrew.lyon@luht.scot.nhs.uk

\section{References}

1 CESDI Project 27/28. www.cemach.org.uk/ publications/p2728/mainreport.pdf (accessed 10 Apr 2003).

2 British Association of Perinatal Medicine/Royal College of Physicians. Development of audit measures and guidelines for good practice in the management of neonatal respiratory distress syndrome. Report of Joint Working Group of British Association of Perinatal Medicine and the Research Unit of Royal College of Physicians. Arch Dis Child 1992;67:1221-7.

3 Costeloe K, Hennessy E, Gibson AT, et al. The EPICure study: outcomes to discharge from hospital for infants born at the threshold of viability. Pediatrics 2000; 196:659-71.

4 Vohra S, Frent G, Campbell V, et al. Effect of polyethylene occlusive skin wrapping on heat loss in very low birth weight infants at delivery: a randomized trial. J Pediatr 1999;134:547-51.

5 Bjorklund L, Hellstrom-Westas L. Reducing heat loss at birth in very preterm infants. Pediatrics 2000;137:739-40.

\section{Haematological consequences of placental insufficiency}

Abnormal development of the placental vasculature is responsible for maternal and fetal impacts of uteroplacental insufficiency. ${ }^{1}$ Umbilical artery (UA) Doppler allows the non-invasive assessment of the severity of this vascular abnormality. UA end diastolic velocities are positive in mild placental insufficiency but are absent or reversed if $60-70 \%$ of the tertiary villous vessels are damaged. This observational study examines the relation between UA end diastolic velocity in growth restricted fetuses and haematological indices at birth. Singleton growth restricted neonates (birth weight $<10$ th centile) had a complete blood count within two hours of delivery. Results were related to the UA end diastolic velocity.
Among 179 participants, UA end diastolic velocity was positive in 108 fetuses $(60 \%)$, absent in $26(14 \%)$, and reversed in $45(25 \%)$. Progressive abnormality of the UA waveform was associated with significant effects on white cell, red cell, and platelet counts (table 1).

White blood cell and nucleated red blood cell counts correlated positively $(r=0.56$, $\mathrm{p}<0.001)$ and were most strongly associated with base deficit and birthweight centile $(\mathrm{p}<0.05)$. The platelet count was predominantly determined by UA blood flow resistance, and red blood cell indices by birthweight centile. Interestingly, the nucleated red blood cell count showed a negative correlation with the haemoglobin concentration $(r=-0.28, \mathrm{p}<0.001)$ and platelet count $(r=-0.31, \mathrm{p}<0.001)$.

Our results indicate that neonatal haematological consequences of placental insufficiency are complex and go beyond the expected polycythaemic response to intrauterine hypoxaemia. ${ }^{2}$ With increasing severity of placental dysfunction, enhanced red cell numbers in response to hypoxaemia are no longer observed, and metabolic compromise may even be associated with decreased red cell mass, thrombocytopenia, and increased nucleated red blood cells and white blood cells. UA Doppler is useful for identifying growth restricted neonates at high risk for these haematological disturbances.

A A Baschat, C R Harman Department of Obstetrics, Gynecology \& Reproductive Sciences, University of Maryland, Baltimore, MD, USA

U Gembruch

Department of Prenatal Medicine and Obstetrics, Friedrich-Wilhelm University, Bonn, Germany

Correspondence to: Dr Baschat, Department of Obstetrics, Gynecology \& Reproductive Sciences, University of Maryland, 405 West Redwood Street, 4th floor, Baltimore, MD 21201-1703, USA: aabaschat@hotmail.com

\section{References}

1 Kingdom JCP, Burrell SJ, Kaufmann P. Pathology and clinical implications of abnormal umbilical artery Doppler waveforms. Ultrasound Obstet Gynecol 1997;9:271-86.

2 Weiner CP, Williamson RA. Evaluation of severe growth retardation using cordocentesis: hematologic and metabolic alterations by etiology. Obstet Gynecol 1989;73:225-9. 